\title{
Dynamic analysis of cable stayed bridge with various patterns of pylon
}

\author{
Sreerag S Kallingal ${ }^{1 *}$, and Priyanka Singh $^{1}$ \\ ${ }^{1}$ Department of Civil Engineering, Amity School of Engineering \& Technology, Amity University \\ Uttar Pradesh, Noida, India
}

\begin{abstract}
The construction of cable stayed bridge increase day by day. The reason behind this is because of the aesthetic beauty and the uniqueness in the structure. This work deals with the study of dynamic analysis of cable stayed bridge with different pylon arrangements. The cable transmits the reaction forces of deck to pylon. Pylon transmits the load of cable to foundation. The pylons ' $\mathrm{H}$ ' shape, 'Inverted $\mathrm{Y}$ ' shape, 'Diamond' shape \& 'Needle' shape arrangement were considered. The MIDAS CIVIL software is used to model and analysis of the cable stayed bridge with various pylon arrangements. The materials and section properties of all four bridges are kept same and the moving load is provided as per IRC:6-2000 loading. In the part of seismic analysis, the time history analysis done and took data of $1940 \mathrm{El}$ Centro earthquake so the nonlinear dynamic behaviour of four bridges investigated. A variety of parameter like, axial forces, displacement and bending moment are analysed. From the result, when complexity increases the behaviour of structure changes. Eventually, the results are compared and concluded that which pattern of pylon shows higher and least performance.
\end{abstract}

\section{Introduction}

The bridge is a structure that designed to be able to carry movable loads from one side to another. The bridge needs to be able to transverse or span a distance. Whether the situation caused by body of water or another difficult subjects beneath the bridge. The bridge is designed from the top down but build from ground to top. Furthermore, structural engineers should consider the how much load and what type of load this bridge should carry, how the deck transfer the load to foundations. In the past years, cable-stayed bridges have been extensively utilized all over the world due to their aesthetic qualities and economic advantages. Numerous intensive studies about cable-stayed bridges are increased. Since this type of bridges can exhibit interesting dynamic behaviours, such as energy transfer between different vibration modes and the beating phenomenon [1]. This type of bridge which has one or more pylons, the bridge deck is supported by the cable and connecting it in to towers. All the components from the cable stayed bride carry their own significant [2]. Cables possess the major role in cable stayed bridge. The cable carries all the load from the deck so the cable must be high strength and should protect from any external treats and also the effect of

\footnotetext{
* Corresponding author: $\underline{\text { sreesiva.kallingal@gmail.com }}$
} 
corrosion can affect the strength of cable [3]. The cable stayed bridge is finest for span lengthier than cantilever bridges and shorter than the suspension bridge. The traffic forces down attached on the road way, the load handover to the towers, the tower experience compression force and tension is acting on the cables $[4,5,6,7]$. The dynamic behaviour of cable stayed bridge with various arrangement of pylons shows different characteristics $[8,9]$. Arrangement of cables having significant role in cable stayed bridge analysis. At the both ends of bridge running between the towers the cable anchored. The anchorage system of cable provide strength to withstand the load acting on the cable, there is different types of anchorage systems are provided in bridge engineering [10,11,12]. Tension and compression are the chief forces that each member on the bridge is going to experience. Tension member will attempt to try and stretch the member or components of the bridge and a compression force is a force that will attempt to shrink the member or components of the bridge. The vehicle load assigning and analysis as per the IRC standards $[13,14,15,16]$. The world is moving on very fast, in civil engineering ability to adapt of new technique is very less. The influence of software in all the sector is very inevitable. Working without software in any sector is difficult. There is lot of software are used to analysis and design in structural zone. The software still improving massively day by day, so the difficulty to use the software decreases. Generally, software like ETABS, STAAD PRO, SAP2000 and MIDAS CIVIL are used. In the project MIDAS CIVIL is used to analysis the bridges.

In this study the dynamic analysis of cable stayed bridge with different pylon patterns are investigated. The Purpose of Pylon or tower is to support the cable system and transmit the forces to foundation. Therefore, it is exposed to large axial forces and bending moments and also controlled by support conditions. Pylon can be made of concrete or steel depending upon various parameters. Pylons are of various types to arrange different cable system, bridge site condition, design features and aesthetics. The pylon patterns are $\mathrm{H}$ shaped, Inverted Y type, Needle type and Delta type or diamond type. For the study purpose time history function of El-Centro, 1940 ground motion was taken and wheel is provided as per IRC:6-2000. There is lot of new bridges are arriving soon to get more effective than previous one. There is lot of studies carrying based on advance in bridges. The anchorage system of cable has significant role in cable stayed bridge.

\section{Methodology}

1. Generating model of cable stayed bridge with different type of pylons in MIDAS CIVIL

2. Defining materials and section properties of cable stayed bridge.

3. Assigning load in the model like self-weight, pretension cable force, vehicle load and seismic load.

4. Assigning vehicle definition by selecting vehicle data base, provide IRC Class A wheel loading and IRC Class $70 \mathrm{R}$ wheel loading.

5. Assigning all load combinations and time history data of El Centro earthquake.

6. After all, perform analysis of cable stayed bridge.

\section{Modelling of cable stayed bridge}

Modelling was done with help of MIDAS CIVIL Software. The software itself give better experience to work. The static and dynamic analysis also done with the MIDAS CIVIL. 


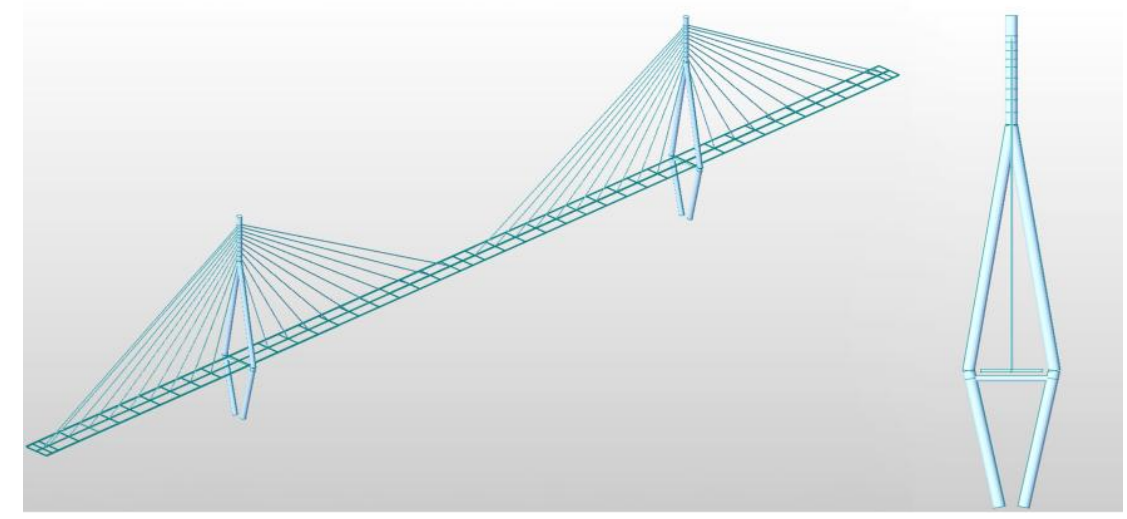

Fig. 1. 3D Model of diamond shape pylon cable stayed bridge

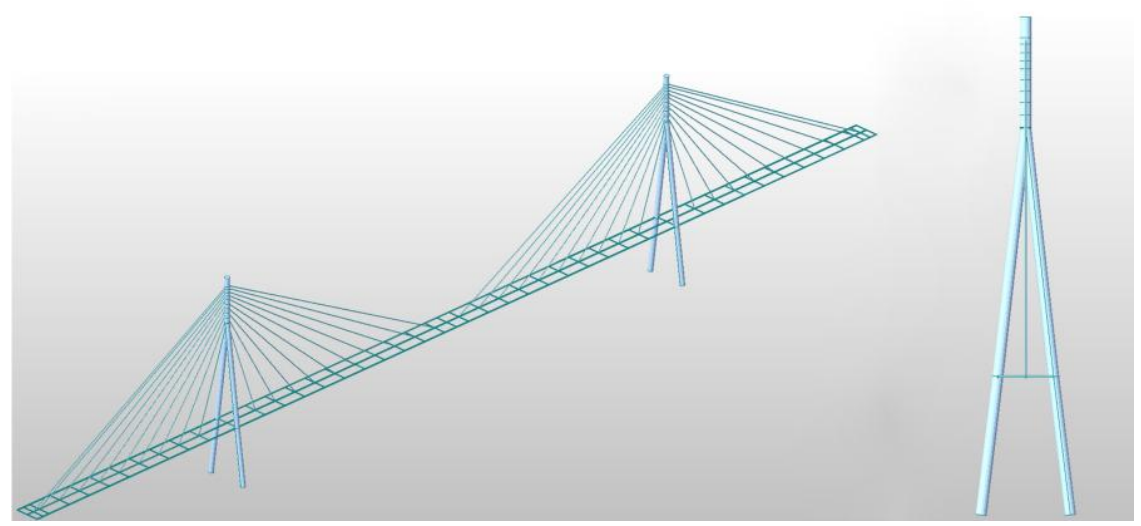

Fig. 2. 3D Model of Inverted Y shape pylon cable stayed bridge

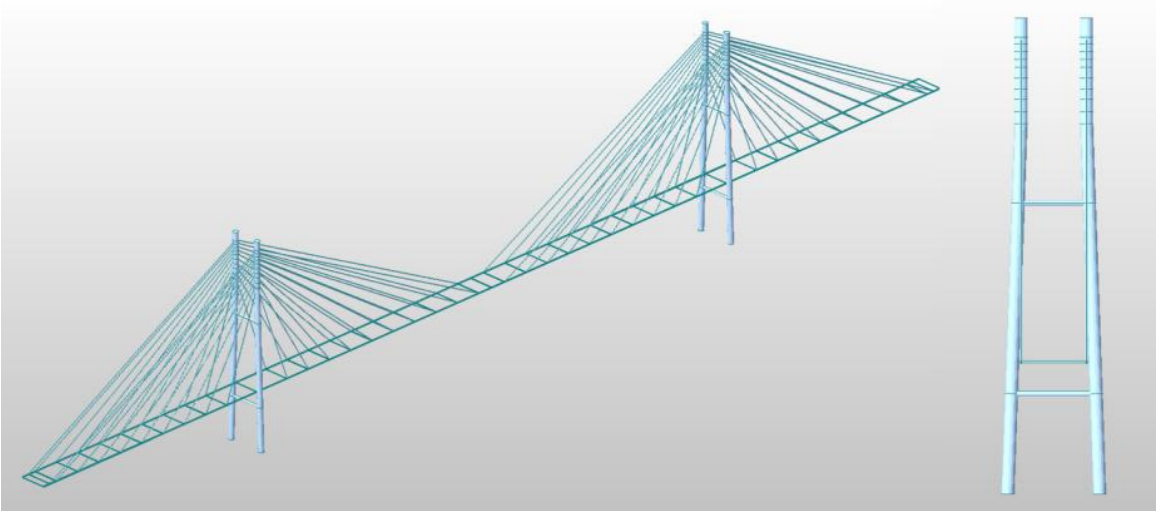

Fig. 3. 3D Model of $\mathrm{H}$ shape pylon cable stayed bridge 


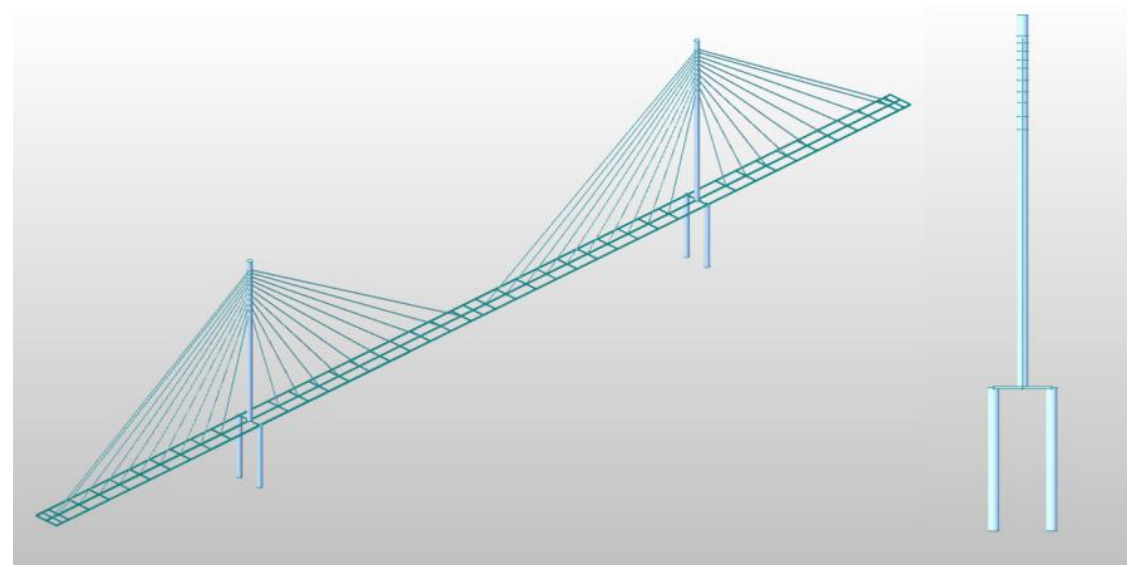

Fig. 4. 3D Model of Needle shape pylon cable stayed bridge

\subsection{Specifications of model}

1. Total length of the bridge $=420 \mathrm{~m}$

2. Width of the deck $=10 \mathrm{~m}$

3. Width of carriage way $=8 \mathrm{~m}$

4. Height of pylon above deck slab $=65 \mathrm{~m}$

5. Height of pylon below deck slab $=25 \mathrm{~m}$

6. Diameter of pylon $=2 \mathrm{~m}$

7. Diameter of cable $=0.35 \mathrm{~m}$

\subsection{Assign of wheel load as per IRC}

The moving load on bridge are classified in to different classes as per IRC [14]. The moving load condition should maintain the criteria provided in IRC. In this study the IRC Class 70R loading and IRC Class A loading are used. In the MIDAS CIVIL they provided the standard IRC loading conditions for different loading as per IRC:6-2000.

\subsubsection{Class 70R loading}

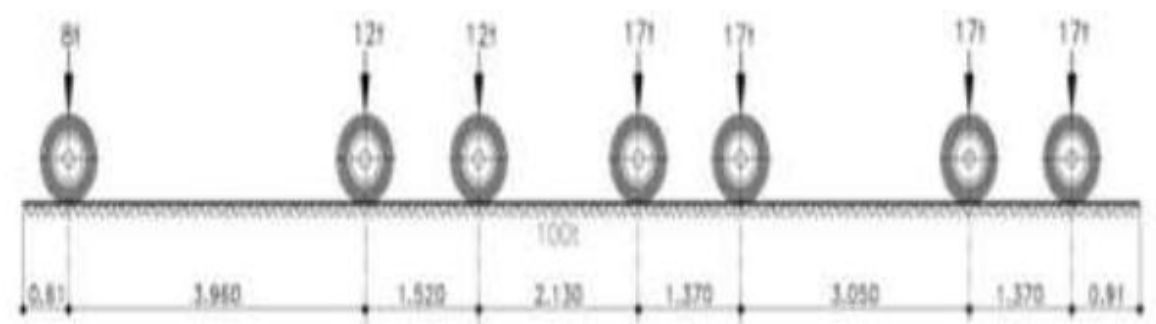

Fig. 5. Class 70R (wheeled)-Longitudinal position 


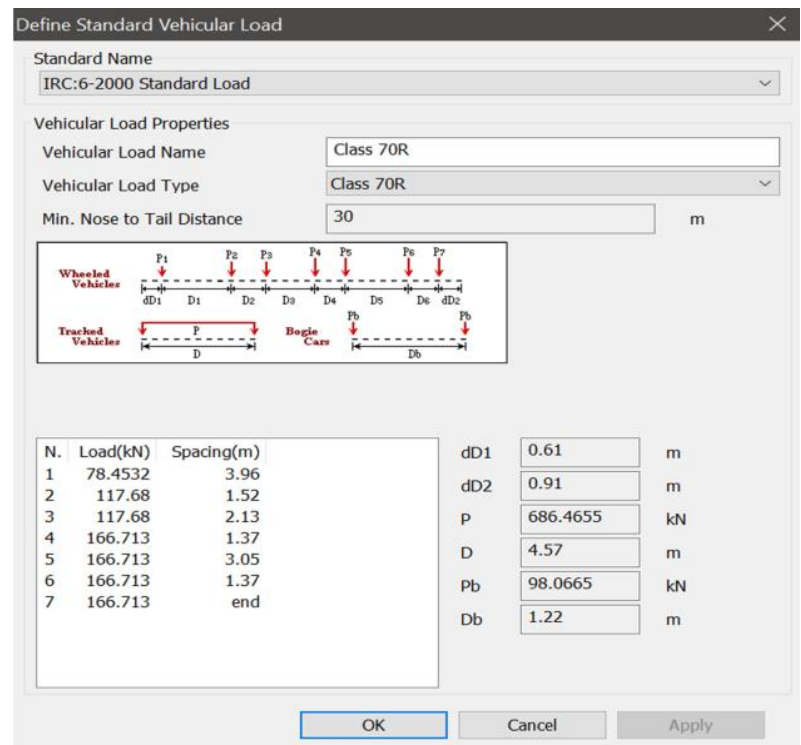

Fig. 6. Class 70R loading as per IRC:6-2000 in MIDAS CIVIL

\subsubsection{Class A loading}

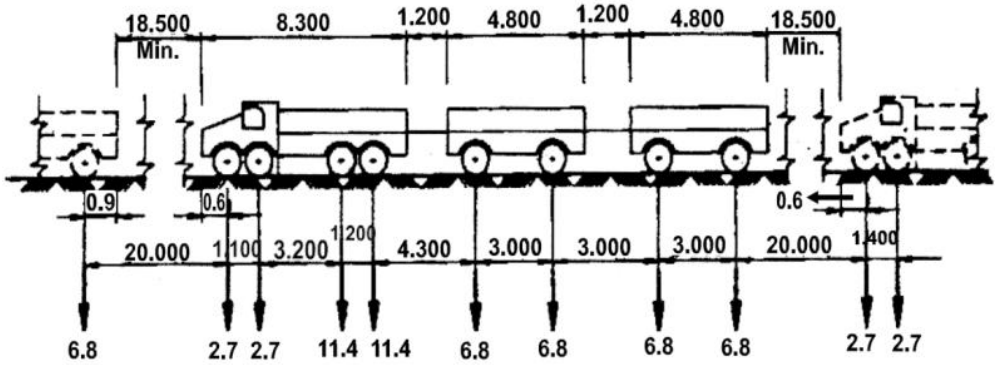

Fig. 7. Class A train of vehicles

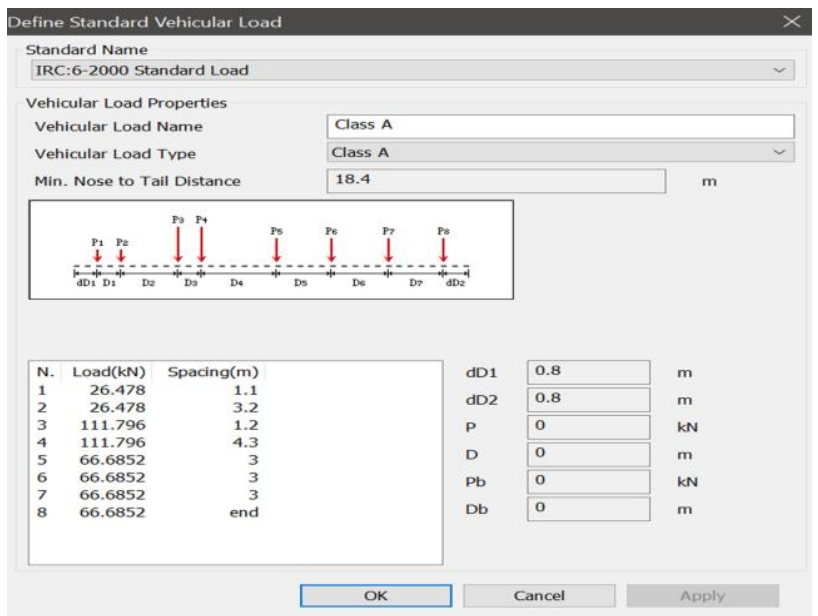

Fig. 8. Class A loading as per IRC:6-2000 in MIDAS CIVIL 


\section{Seismic load}

The structural damping of cable stayed bridge are less, hence the rise in span of cable stayed bridge elevates several concerns about the behaviour under dynamic loads like wind, earthquake and vehicular traffic load. These bridges infrequently experience extreme loads, specifically during a strong earthquake. The time history data of El Centro,1940 earthquake is provided to run the time history analysis. The earthquake acting in all direction so the bridge could experience the action of earthquake in various direction.

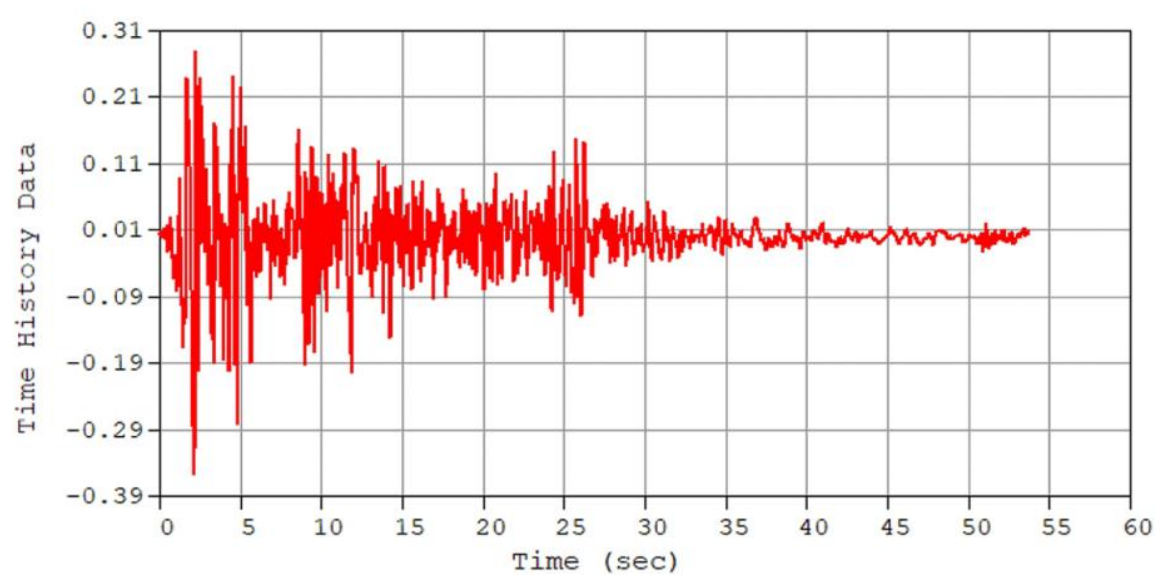

Fig. 9. 1940 El Centro ground motion

\section{Result and Discussion}

\subsection{Mode shapes}
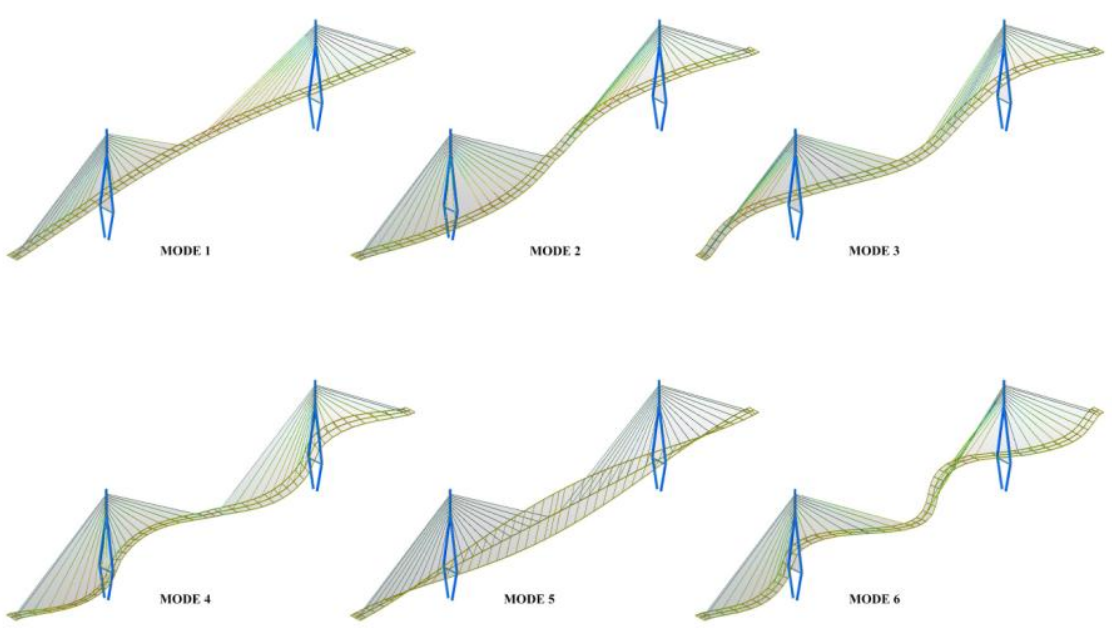

Fig. 10. Mode shapes of Diamond pylon. 

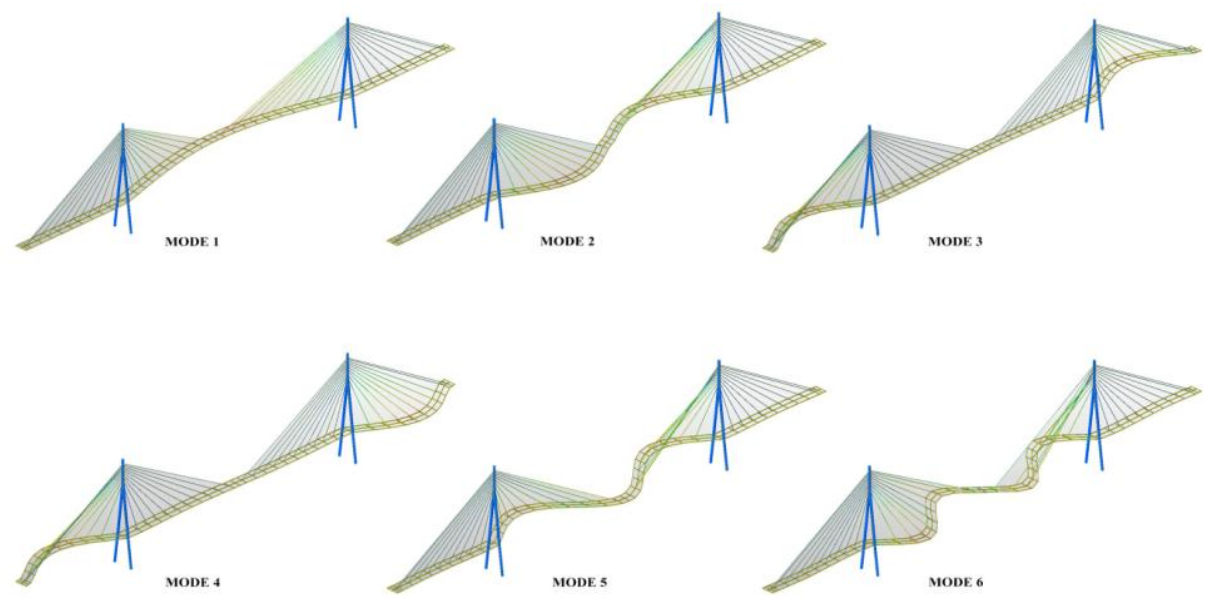

Fig. 11. Mode shapes of Inverted Y pylon
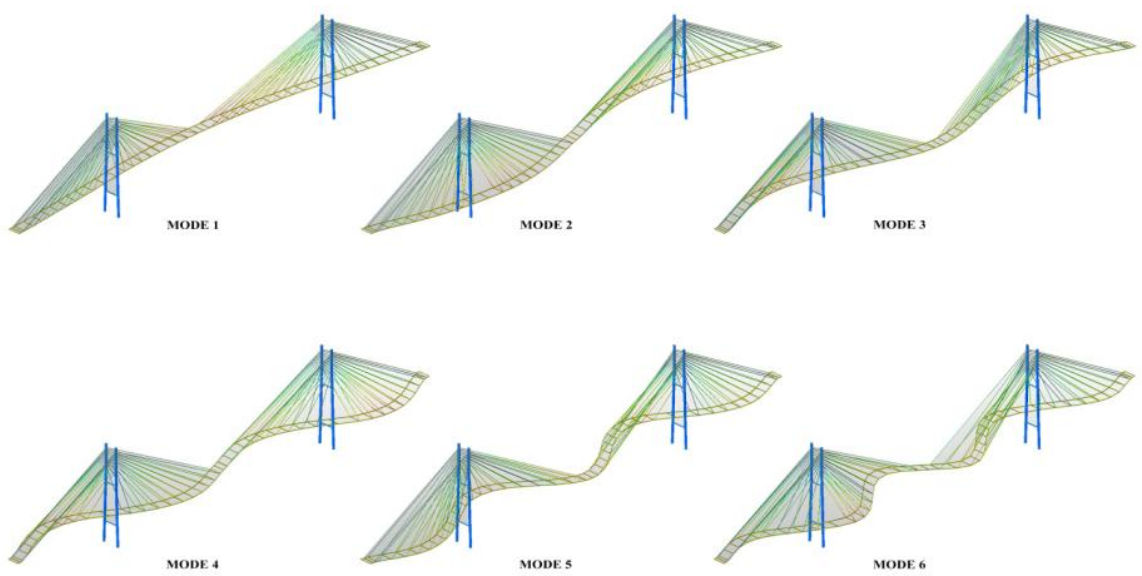

Fig. 12. Mode shapes of H pylon
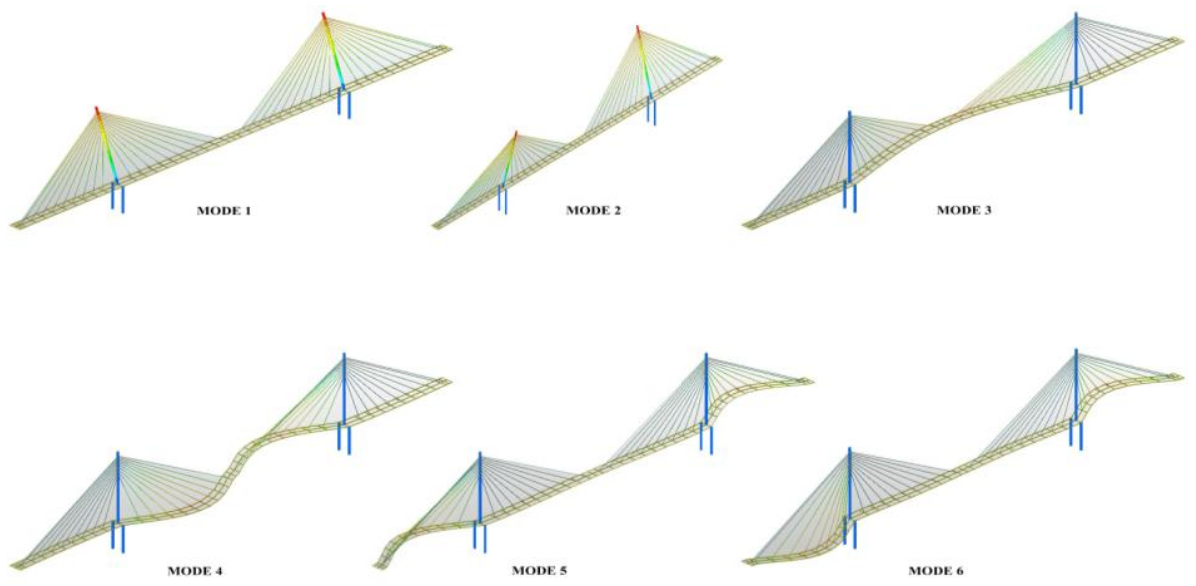

Fig. 13. Mode shapes of Needle pylon 
Table 1. Vibration mode shapes

\begin{tabular}{|c|c|c|c|}
\hline $\begin{array}{c}\begin{array}{c}\text { Shape of } \\
\text { Pylon }\end{array} \\
\end{array}$ & Mode & $\begin{array}{c}\text { Frequency } \\
(\text { HZ) }\end{array}$ & $\begin{array}{c}\text { Time Period } \\
\text { (sec) }\end{array}$ \\
\hline \multirow{6}{*}{ Diamond } & Mode 1 & 0.004779 & 209.239761 \\
\hline & Mode 2 & 0.012009 & 83.270236 \\
\hline & Mode 3 & 0.016322 & 61.265768 \\
\hline & Mode 4 & 0.019913 & 50.217709 \\
\hline & Mode 5 & 0.020704 & 48.299823 \\
\hline & Mode 6 & 0.025217 & 39.656543 \\
\hline \multirow{6}{*}{ Inverted $\mathrm{Y}$} & Mode 1 & 0.008407 & 118.949787 \\
\hline & Mode 2 & 0.019204 & 52.071709 \\
\hline & Mode 3 & 0.023007 & 43.465163 \\
\hline & Mode 4 & 0.023094 & 43.301391 \\
\hline & Mode 5 & 0.028553 & 35.022385 \\
\hline & Mode 6 & 0.040155 & 24.903604 \\
\hline \multirow{6}{*}{$\mathrm{H}$} & Mode 1 & 0.001953 & 512.007412 \\
\hline & Mode 2 & 0.004947 & 202.157180 \\
\hline & Mode 3 & 0.006801 & 147.031343 \\
\hline & Mode 4 & 0.008399 & 119.066476 \\
\hline & Mode 5 & 0.010617 & 94.184331 \\
\hline & Mode 6 & 0.014361 & 69.632041 \\
\hline \multirow{6}{*}{ Needle } & Mode 1 & 0.007305 & 136.894765 \\
\hline & Mode 2 & 0.007305 & 136.894759 \\
\hline & Mode 3 & 0.008405 & 118.972664 \\
\hline & Mode 4 & 0.019202 & 52.079043 \\
\hline & Mode 5 & 0.023114 & 43.263072 \\
\hline & Mode 6 & 0.023125 & 43.243034 \\
\hline
\end{tabular}

\subsection{Graphical illustrations}

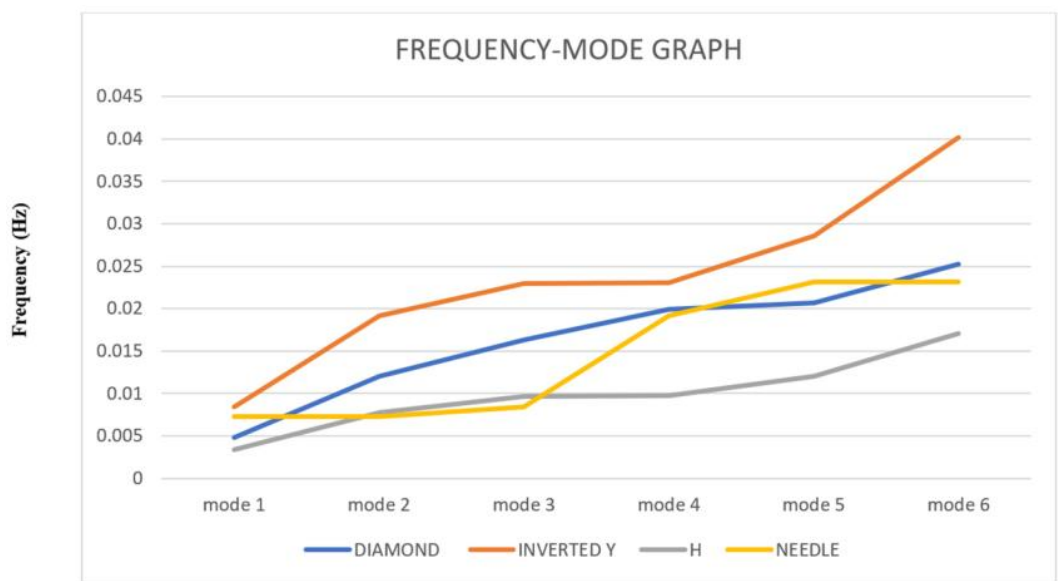

Fig. 14. Frequency-mode graph 


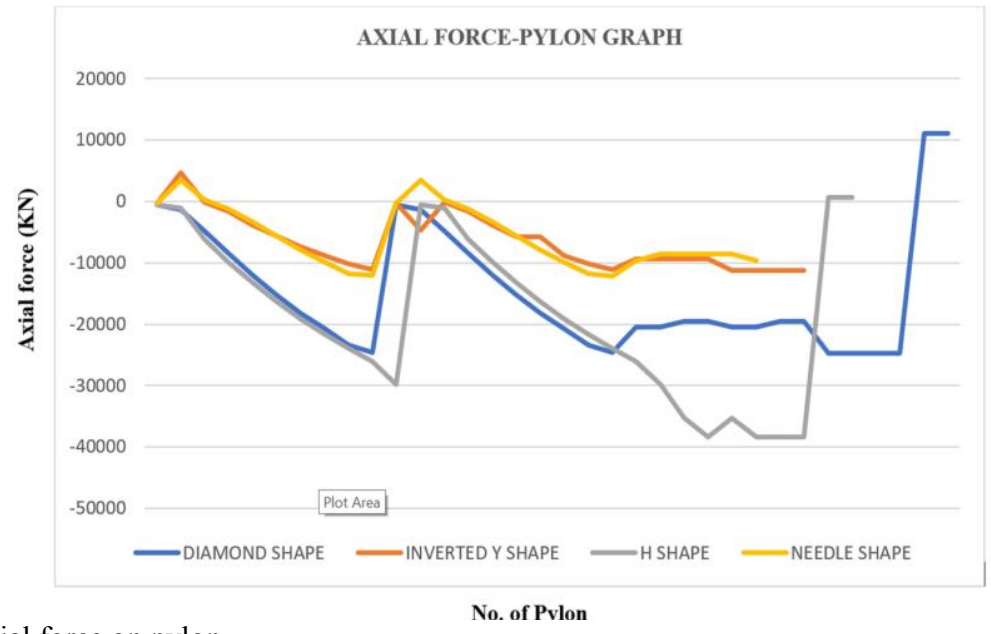

Fig. 15. Axial force on pylon

SHEAR FORCE-PYLON GRAPH

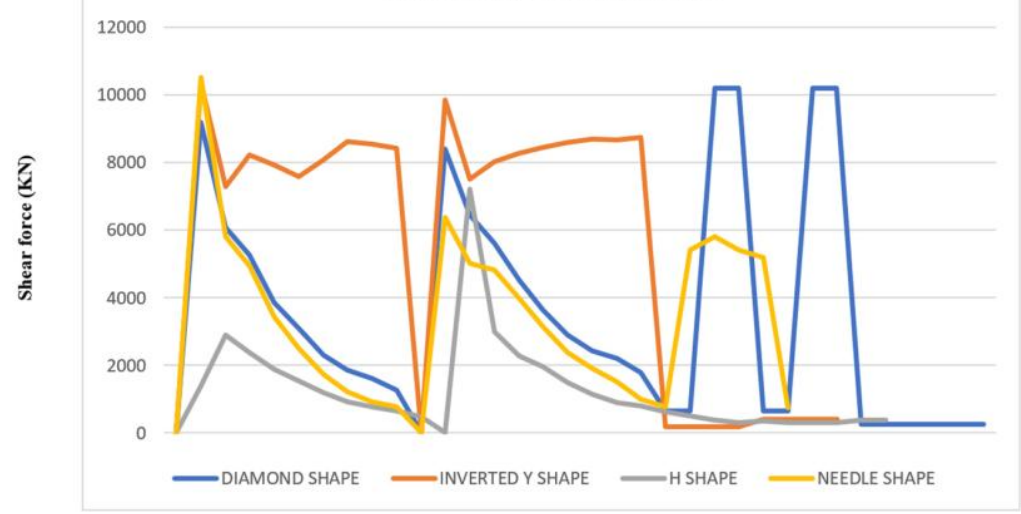

Fig. 16. Shear force on pylon

No. of Pvlon

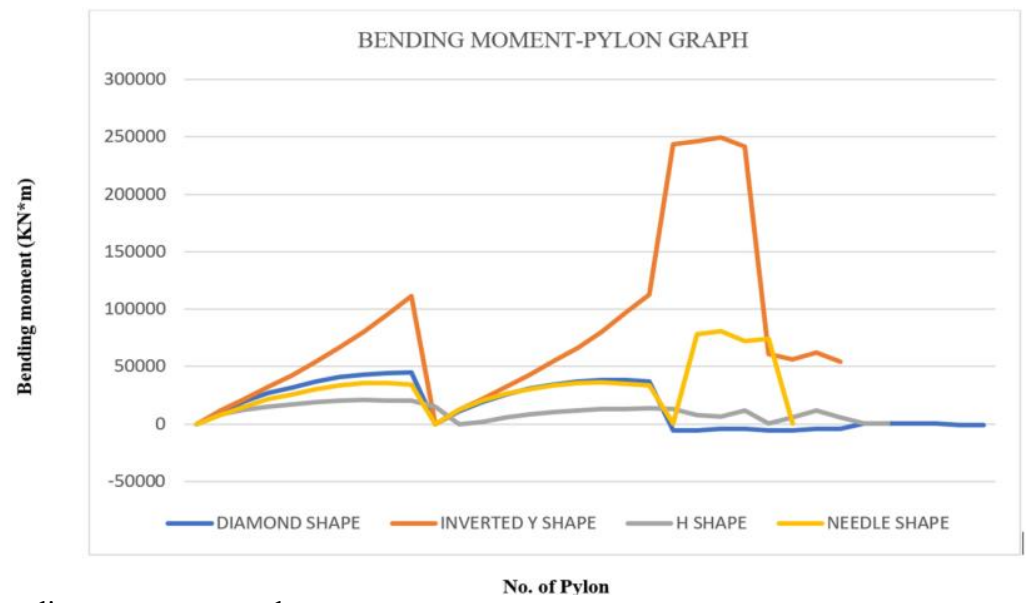

Fig. 17. Bending moment on pylon 


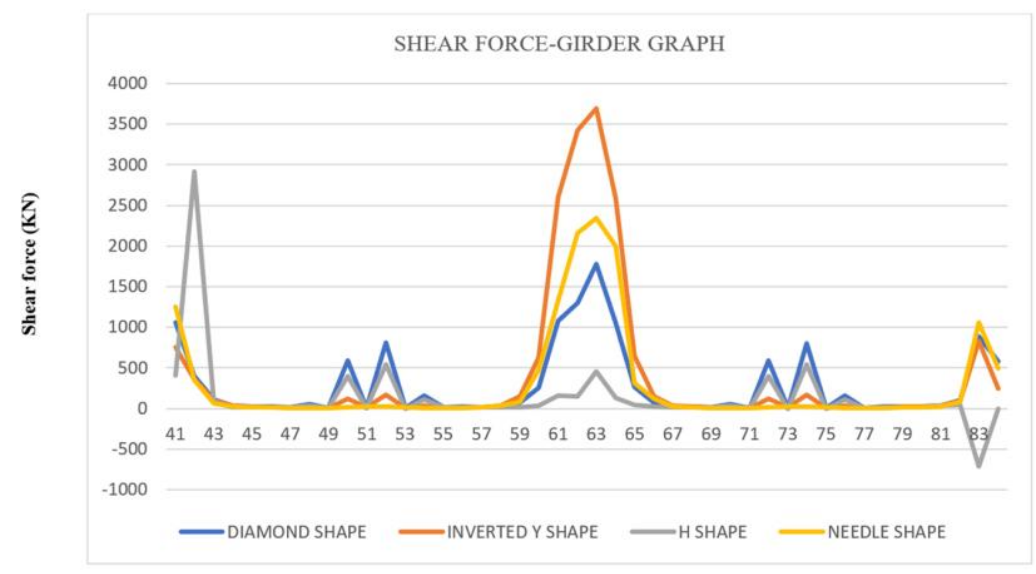

Fig. 18. Shear force on girder

No. of Girder

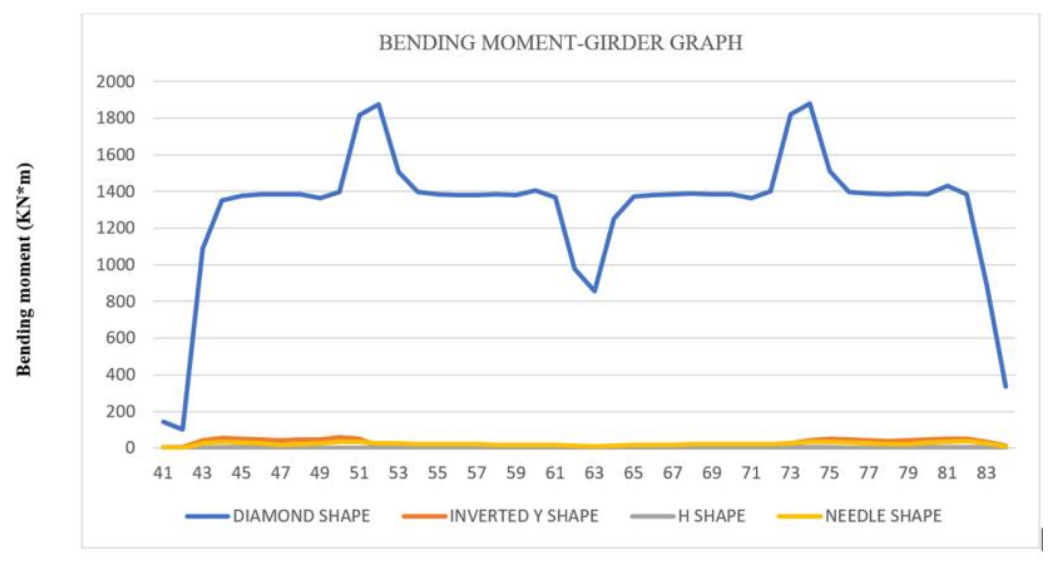

Fig. 19. Bending moment on girder

No. of Girder

From the frequency vs mode graph, we can state that the least frequency value and high time period occurred at mode 1 . The $\mathrm{H}$ shape pylon cable stayed bridge having least frequency value compared to other and the high frequency value occurred in Inverted $\mathrm{Y}$ shape pylon cable stayed bridge (Fig.14). The pylon axial force in the Diamond shape pylon cable stayed bridge have developed maximum (11094.84 KN) compared to other pylons and the minimum axial force $(-38411.3 \mathrm{KN})$ developed on $\mathrm{H}$ shape pylon cable stayed bridge (Fig.15). The pylon shear force on the inverted Y shape pylon cable stayed bridge have developed maximum $(10526.87 \mathrm{KN})$ compared to others and the minimum $(243.36$ $\mathrm{KN}$ ) shear force occurred in Diamond shaped pylon cable stayed bridge (Fig.16). The pylon bending moment in the inverted $\mathrm{Y}$ shape pylon cable stayed bridge have maximum $(249383.10 \mathrm{KN} * \mathrm{~m})$ compared to other and minimum $\left(-5687.16 \mathrm{KN}^{*} \mathrm{~m}\right)$ bending moment value occurred in Diamond shape pylon cable stayed bridge (Fig 17). The Shear force on girder the inverted $\mathrm{Y}$ shape shows maximum $(3689.5 \mathrm{KN})$ than others and the minimum (714.64 KN) shear force acting on $\mathrm{H}$ shape pylon cable stayed bridge girder (Fig.18). The bending moment on girder the Diamond shape pylon cable stayed bridge shows maximum $\left(1876 \mathrm{KN}^{*} \mathrm{~m}\right)$ value than the others and minimum $\left(1.4 \mathrm{KN}^{*} \mathrm{~m}\right)$ moment developed on $\mathrm{H}$ shape pylon cable stayed bridge girder (Fig.19). 


\section{Conclusions}

The above study derived the conclusion about dynamic behaviour of cable stayed bridge with various patterns of pylons. when the increase in complexity of the structure increases the risk of dynamic behaviour. The cable stayed bridge is a complex structure so the dynamic behaviour also complex. From the values Inverted $\mathrm{Y}$ shape and Diamond shape pylon cable stayed bridge shows high values of axial force, shear force and bending moment in both pylon and girder. As well as the Inverted Y shape shows high frequency compared to others. The $\mathrm{H}$ shape pylon cable stayed bridge shows more stable feature in dynamic response compare to others. So, the complex structure needs more care in design, in selection of materials and need better supervision. The various type arrangements in pylon of cable stayed bridge are analysed. Inverted Y shape pylon, Diamond shape pylon, $\mathrm{H}$ shape pylon and needle shape pylon these are the various arrangements of pylons used in modelling. The modelling by MIDAS CIVIL software. The provided load cases are dead load, moving load and seismic load. The El Centro ground motion data are used for dynamic analysis. The dynamic response of bridge in 6 modes are calculated. The results like vibration mode shapes, axial force, shear force and bending moment are finally illustrated graphically.

\section{References}

1. G. Fabrizio, P. Lonetti, A. Pascuzzo, Dynamic analysis of cable-stayed bridges affected by accidental failure mechanisms under moving loads, Mathematical Problems in Engineering 2013, 302706 (2013)

2. S.P. Thakkar, Parametric Study of Shapes of Pylon for Cable Stayed Bridge, Nirma University Journal of Engineering and Technology 2, 9-16 (2000)

3. C. Li, Cable Force Adjustment of Torsion Cable-Stayed Bridge, Journal of Civil, Construction and Environmental Engineering 3, 106-110 (2018)

4. P.S. Misal, N.R. Dhamge, A.A. Dhawale, Dynamic Analysis of Cable Stayed Bridge for Various Cable Patterns, International Journal of Innovations in Engineering and Science 4, 97-102 (2019)

5. D. Animesh, A. Dutta, S. Talukdar, Efficient dynamic analysis of cable-stayed bridges under vehicular movement using space and time adaptivity, Finite elements in analysis and design 40, 407-424 (2004)

6. S. Mitao, D. Cao, W. Zhu, Dynamic analysis of a cable-stayed bridge subjected to a continuous sequence of moving forces, Advances in Mechanical Engineering 8, 12 (2016)

7. M.Sh. Shankar, A. Nagar, T. Soumya, Dynamic Analysis of Cable Stayed Bridge under Moving Loads with the Effect of Corrosion of Cables, International Journal of Engineering Research \& Technology 4, 651-660 (2015)

8. G.M. Savaliya, A. Desai, S.A. Vasanwala, Static and dynamic analysis of cable-stayed suspension hybrid bridge \& validation, International Journal of Advanced Research in Engineering and Technology 6, 91-98 (2015)

9. Y.B. Janger, M.R. Suresh, Time-History Analysis of a Cable Stayed Bridge for Various Spans and Pylon Height, International Research Journal of Engineering and Technology 5, 166-174 (2018)

10. N. Jianguo, M. Tao, J. Fan, Research on cable anchorage systems for self-anchored suspension bridges with steel box girders, Journal of Bridge Engineering 
11. 16(5), 633-643 (2011)

12. Q-T. Su, et al. Investigation on the horizontal mechanical behavior of steelconcrete composite cable-pylon anchorage, Journal of Constructional Steel Research 72, 267 $275(2012)$

13. C.J. Francisco, et al. Structural monitoring of cable stayed bridge during rehabilitation, 4th International Conference on Structural Health Monitoring of Intelligent Infrastructure (SHMII-4), Zurich, Switzerland (2009)

14. K. Praveen, R. Gowda, B. Arjun, Analysis of Cable Stayed Bridge under the Action of Vehicular and Seismic Loads, International Journal of Scientific Development and Research 2, 17-22 (2017)

15. IRC:6-2000, Standard code and specifications for road bridges, Loads and stresses.

16. Z. Iqra, P. Singh, Analysis and Design of Deck Slab Bridge, Journal of Civil Engineering and Environmental Technology 3, 517-522 (2016)

17. P. Singh, M.J. Baig, B. Pandey, K. Papreja, Designing and 3-D Modelling of a Sustainable Cable Stayed Bridge-A Case Study, E3S Web of Conferences 220, 01070 (2020) 